\title{
Preformulation and Evaluation of Antibacterial and Anti-Inflammatory Activities of Saccharum spontaneum Linne Root Extract Cream
}

\author{
A. M. R. Lapuz, R. D. A. Arabiran, T. M. Sembrano, J. R. Albaniel, J. C. Paet, and H. A. Maini
}

\begin{abstract}
Saccharum spontaneum Linn. (Fam. Poaceae) root extract have been pre-formulated into a cream and evaluated for its antibacterial and anti-inflammatory activities. Phytochemical screening done on the lyophilized plant extract have shown the presence of carbohydrates, glycosides, alkaloids, tannins and flavonoids.

Antibacterial activities of the root extract and pre-formulated cream were evaluated by Kirby-Bauer Disk Diffusion Method against three microorganisms, namely, Staphylococcus aureus, Staphylococcus epidermidis, and Pseudomonas aeruginosa. Likewise, the pre-formulated cream was evaluated for its anti-inflammatory activity using mice injected with $0.1 \mathrm{~mL}$ of $1 \%$ carrageenan solution to induce inflammation. The degree of inflammation was measured using a digital Vernier caliper at $\mathbf{0 \text { , }}$ 1,2 , and 3 hours after the stimulus was made.

Evaluation results showed that the pre-formulated $2 \%$ root extract cream of the plant possess anti-inflammatory activity rather than antibacterial activity.
\end{abstract}

Index Terms-Antibacterial, anti-inflammatory, Kirby-Bauer disk diffusion method, S. spontaneum Linn. cream.

\section{INTRODUCTION}

The Philippines, being a tropical country, is a home for diverse species of plants that thrive and grow all over the archipelago. These plants have provided food, clothing, fuel, shelter, and many other necessities in life especially, herbal preparations which native folks used for their claimed medicinal values. One of these plants is Saccharum spontaneum Linn., believed by some folks who practice traditional medicine in the rural areas as having diuretic effect, thus, the root extract has been used for the treatment of urinary tract infection. Sometimes, freshly prepared stems cut into pieces are chewed to relieve stomach pain. $S$. spontaneum L. is found abundantly throughout the Philippines. It usually grows in wide open uncultivated areas at low and medium elevations ascending to 1,500 metres. It can also be found in other parts of Asia, from India to Southern China and from Malaya to Polynesia [1] .

Studies conducted revealed that $S$. spontaneum Linn. contained specific active constituents which contribute to its

Manuscript received March 2, 2015; revised June 30, 2015. Travel support for this paper to be presented in ICABC 2015 was obtained from CRECE of the Adamson University.

A. M. R. Lapuz, R. D. A. Arabiran, T. M. Sembrano, J. R. Albaniel, and J. C. Paet are with Adamson University, San Marcelino St., Ermita, Manila, Philippines, Filipino.

H. A. Maini is with Adamson University, San Marcelino St., Ermita, Manila, Philippines (e-mail: hedymaini@yahoo.com). effect against certain microbes. Other studies confirmed that the extract has an anti-inflammatory effect and can also be used to treat kidney stones [2].

This characteristic has been capitalized by the researchers for its possible formulation as a cream consisting of the $S$. spontaneum Linn. root extract as the main ingredient, thus, providing confirmation on its claimed antibacterial and anti-inflammatory effects. Apart from this, it can provide a more accessible and readily available alternative treatment to patients afflicted with skin disorders. The formulation of a topical cream from $S$. spontaneum Linn. root extract is relatively cheaper considering that the plant is found all over the Philippines in waste areas.

The study is significant and novel since formulation of any dosage form from $S$. spontaneum Linn. extract has never been done.

\section{CONCEPTUAL FRAMEWORK}

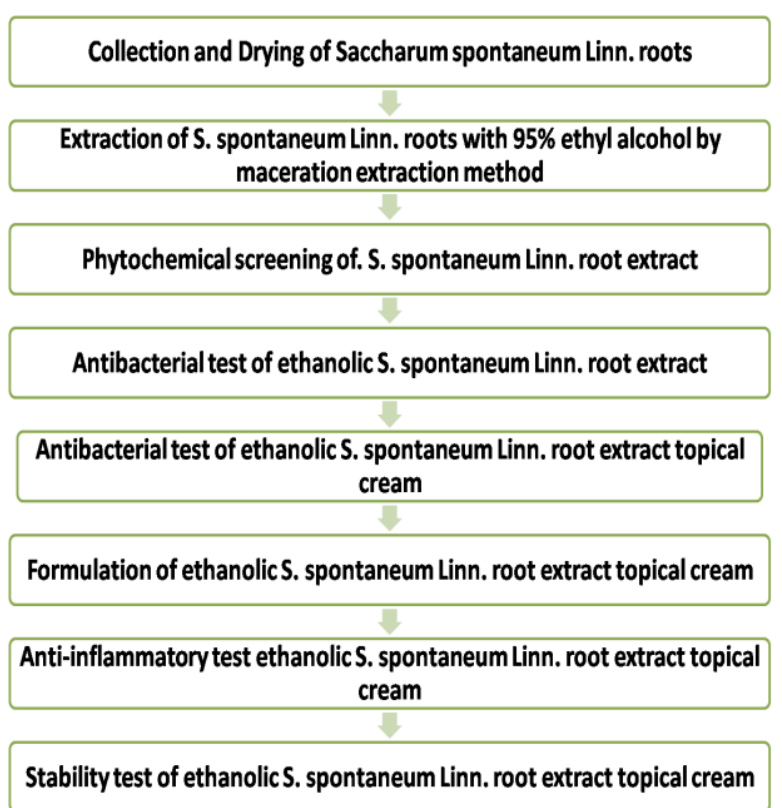

Fig. 1. Conceptual framework of the evaluation of S. spontaneum Linne.

The study on the root extract of $S$. spontaneum Linn. was prompted by claims that the plant exhibits useful activities and that few of our local people have used the root extract as a diuretic, galactagogue, for treating gastrointestinal and gynecological problems [3]. In addition to this, the high cost of drugs such as antibiotics and anti-inflammatory agents contributed to the interest of the researchers to find proof that indeed, S. spontaneum Linne may be a natural source that can 
be used as an alternative medicine for such needs. There is no other way by which this can be proven except by conducting a scientific investigation on the plant. The researchers will adopt the conceptual framework as shown in Fig. 1. The study was concerned with the formulation and evaluation of antibacterial and anti-inflammatory properties of $S$. spontaneum Linn. root extract and its formulation as cream.

\section{Methodology}

\section{A. Collection, Extraction and Preparation of the Plant Sample}

Samples of S. spontaneum Linn. was collected from Arayat, Pampanga and authenticated by the Botany Division of the Philippine National Museum; air dried, and extracted with $95 \%$ ethanol by soaking it for 48 hours with frequent agitation. The resulting mixture was filtered in vacuo and the filtrate concentrated under reduced pressure at $40^{\circ} \mathrm{C}$ and then lyophilized. The resulting powdered, lyophilized extract was used to prepare solutions containing $0.5 \%, 1 \%, 1.5 \%$, and $2 \%$ weight of extract per volume of the solvent used.

\section{B. Phytochemical Screening of the Plant Extract}

The solution of the plant extract underwent phytochemical screening for the presence of plant constituents.

\section{1) Test for carbohydrates - Molisch's test}

A pinch of the powdered extract was dissolved in one $\mathrm{mL}$ hot distilled water and two drops of Molisch's reagent (a 15 percent alcoholic solution of $\alpha$-naphthol) was added. The tube was inclined and an approximated one $\mathrm{mL}$ of concentrated sulfuric acid was poured down slowly. A reddish-violet zone was produced at the point of contact which indicated presence of carbohydrates [4].

\section{2) Test for glycosides - Fehling's test}

A pinch of the powdered extract was dissolved in one $\mathrm{mL}$ hot distilled water. Two $\mathrm{mL}$ of diluted hydrochloric acid is added and placed in a water bath. The solution was neutralized with sodium hydroxide. Two $\mathrm{mL}$ of each Fehling's A and Fehling's B solution were added and heated on a water bath for two minutes. A brick-red precipitate was observed which indicated the presence of glycosides [5].

\section{3) Test for alkaloids - Mayer's/ Dragendorff's test}

A pinch of the powdered extract was dissolved in two to three $\mathrm{mL}$ hot distilled water and few drops of Mayer's reagent (potassium mercuric iodide solution) or Dragendorff's reagent (potassium bismuth iodide solution) was added. A white brown precipitate or orange brown precipitate was formed which indicated the presence of alkaloids [3].

\section{4) Test for tannins - Ferric Chloride test}

A pinch of the powdered extract was dissolved in one $\mathrm{mL}$ of hot distilled water and two drops of ferric chloride solution is added. A blue-black color was formed which indicated the presence of hydrolysable tannins while a brownish-green color was formed due to the presence of condensed tannins [3].

\section{5) Test for flavonoids - Bate-Smith-Metcalf test}

One $\mathrm{mL}$ of $10 \%$ ethanolic root extract was placed in a test tube and $0.5 \mathrm{~mL}$ of concentrated hydrochloric acid and magnesium metal was added. A reddish color was formed which indicated the presence of flavonoids [5].

\section{Antimicrobial Evaluation}

The same solutions of the root extract underwent testing using Kirby-Bauer disk diffusion method for its antibacterial activity together with the formulated cream against three microorganisms, namely, S. aureus, S. epidermidis, and $P$. aeruginosa. Sterile filter paper disks were placed and infused with the S. spontaneum Linn. root extracts, positive standard (Polymyxin B Sulfate + Bacitracin Zinc + Neomycin Sulfate), and negative control ( $95 \%$ ethanol) on separate plates of prepared culture medium. The plates were incubated at $37^{\circ} \mathrm{C}$ for $18-24 \mathrm{hrs}$. This was done in triplicate. After incubation, the zone of inhibitions of the $S$. spontaneum Linn. root extracts of various concentrations, standard and negative controls were measured using a digital Vernier caliper and recorded [6].

\section{Formulation of Saccharum Spontaneum Linne Extract}

The cream was formulated by weighing and measuring the desired amounts of ingredients as shown in Table I. Cetostearyl alcohol was melted in an evaporating dish over a water bath to a temperature no higher than $60^{\circ} \mathrm{C}$. Once melted, the liquid paraffin was added and then removed from heat. The mixture was stirred to form the oily phase. The freshly boiled and cooled purified water was placed in a beaker, transferred and heated to $60^{\circ} \mathrm{C}$. The $S$. spontaneum Linn. root extract was incorporated into the freshly boiled and cooled purified water and then removed from heat. The mixture was stirred to form the aqueous phase. When both phases have been cooled to about $60^{\circ} \mathrm{C}$, the aqueous phase was added to the oily phase with constant, but not too vigorous stirring to form a uniform phase. The mixture was stirred until cool enough to pack. Fifty grams of the product was weighed, packed in a suitable jar and then labeled [7].

TABLE I: FORMULATION OF THE S. SPONTANEUM LINN. ROOT EXTRACT CREAM

\begin{tabular}{|c|c|c|c|c|c|}
\hline \multirow{2}{*}{ Ingredients (in grams) } & \multicolumn{5}{|c|}{ Cream Formulations } \\
\cline { 2 - 6 } & $\begin{array}{c}\text { Place } \\
\text { bo }\end{array}$ & $\mathbf{0 . 5 \%}$ & $\mathbf{1 \%}$ & $\mathbf{1 . 5 \%}$ & $\mathbf{2 \%}$ \\
\hline Crude ethanolic extract & 0 & 5.00 & 10.00 & 15.00 & 20.00 \\
\hline Cetostearyl alcohol & 50.25 & 50.00 & 49.75 & 49.50 & 49.25 \\
\hline Liquid paraffin & $\begin{array}{c}502.5 \\
0\end{array}$ & $\begin{array}{c}500.0 \\
0\end{array}$ & 497.50 & 495.00 & 492.50 \\
\hline Distilled water & $\begin{array}{c}447.2 \\
5\end{array}$ & $\begin{array}{c}445.0 \\
0\end{array}$ & 442.75 & 440.50 & 438.25 \\
\hline To make & $\mathbf{1 0 0 0}$ & $\mathbf{1 0 0 0}$ & $\mathbf{1 0 0 0}$ & $\mathbf{1 0 0 0}$ & $\mathbf{1 0 0 0}$ \\
\hline
\end{tabular}

\section{E. Tests for Properties of Creams}

Tests for determining the properties of the formulated cream such as spreadability, washability and $\mathrm{pH}$ were employed using the methods described by [8], [9].

Washability test was employed by rubbing small amounts of the cream on the hand and washing off with warm water without using soap [9]. The spreadability of the cream was measured by using two slides to compress the sample with equal thickness and the time required to separate the two slides was recorded [9]. The last test employed was the determination of $\mathrm{pH}$ of the sample using a $\mathrm{pH}$ meter [8]. 


\section{F. Animal Rearing}

Male Swiss albino mice weighing between 18 - 25 grams were used as test animals for the anti-inflammatory activity evaluation of the formulated cream. They were maintained in large polypropylene cages and were acclimatized to animal house condition at the College of Pharmacy, Adamson University. They were fed with commercial pellet and have free access to water.

\section{G. Anti-inflammatory Activity Evaluation}

The experimental animals were divided into six groups having 6 mice in each group. Group I (control group) received the base cream only; Groups II - V (test groups) received the formulations containing different concentrations of the $S$. spontaneum Linne ethanolic extract at the rate of $0.5 \%, 1 \%$, $1.5 \%$ and $2 \%$, respectively, by topical administration; Group VI (standard group) received the Diclofenac sodium $1 \%$ gel by topical administration.

The carrageenan-induced paw edema test was used to evaluate the anti-inflammatory activity of the formulation. The animals pre-treated with the formulation or Diclofenac sodium one hour before were injected with $0.1 \mathrm{~mL}$ of $1 \%$ carrageenan solution into the plantar tissue of the right hind paw of each mouse. The initial paw volume was immediately measured after carrageenan application at 0, 1, 2, 3, and 4 hours after the stimulus [10], [11].

\section{H. Statistical Analysis}

The data was presented as mean \pm standard deviation of parallel measurements. The difference between the treatment groups was analyzed using One-way ANOVA followed by Dunnett's test. A $p$-value of less than 0.05 is considered significant [10].

\section{RESULTS AND DISCUSSION}

\section{A. Phytochemical Screening Results}

Phytochemical screening results of the plant extract of $S$. spontaneum Linne indicated the presence of carbohydrates, glycosides, alkaloids, condensed tannins, and flavonoids. These results, particularly the presence of flavonoids, was substantiated by the work of [3]. In the evaluation of [3], a total flavonoid content for S. spontaneum Linne ethanolic root extract determined by colorimetric method, was found to be $48.60 \pm 2.17 \mathrm{mcg}$ rutin per $10 \mathrm{mg}$ of the extract. In another study, phytochemical screening and estimation of total phenolic content and total flavonoid content was performed on the roots of $S$. spontaneum L. The total phenolic content was determined by modified Folin-Ciocalteu method. The results showed that the total phenolic content present in ethanolic root extract is $254.42 \pm 1.82 \mathrm{mcg}$ gallic acid per 10 $\mathrm{mg}$ of the extract [12].

\section{B. Results of Tests for Creams}

Table II shows the results for the tests conducted on the formulated $S$. spontaneum Linn. root extract cream in terms of washability, spreadability and $\mathrm{pH}$. The formulated cream left a greasy texture in the skin even after washing with warm water which indicates that the cream was not easily washable.
In testing for the spreadability of the formulated cream, a small portion of the cream was placed in between glass slides and compressed until equal thickness was obtained. The time it takes to separate the two slides was recorded. Based on the table, the time required ranges from $2-3$ seconds, indicating an ease of spread. A neutral $\mathrm{pH}$ was obtained for the formulated cream which was within the range of allowable $\mathrm{pH}$ of 4 to 8 for the skin to avoid irritation.

TABLE II: RESULTS OF TESTS FOR THE FORMULATED S. SPONTANEUM LINN. ROOT EXTRACT CREAM

\begin{tabular}{|c|c|}
\hline \multicolumn{1}{c|}{ Tests } & \multicolumn{1}{c|}{ Results } \\
\hline Washability & All creams leave a greasy feel when washed. \\
\hline $\begin{array}{l}\text { Spreadabilit } \\
\text { y }\end{array}$ & Measured in seconds \\
\hline Placebo & 2.15 seconds \\
\hline $0.5 \%$ & 2.50 seconds \\
\hline $1.0 \%$ & 2.05 seconds \\
\hline $1.5 \%$ & 2.22 seconds \\
\hline $2.0 \%$ & 2.42 seconds \\
\hline $\mathrm{pH}$ & All creams formulated were neutral in $\mathrm{pH}$ \\
\hline
\end{tabular}

The plant extracts and formulated cream were evaluated for antimicrobial and anti-inflammatory activities. The antimicrobial evaluation was conducted against Staphylococcus aureus, Staphylococcus epidermidis and Pseudomonas aeruginosa. These microbes used for evaluation were chosen for the very reason that all of them are the causative agents of common diseases that affects man. $P$. aeruginosa is an opportunistic pathogen that causes varied infections of the urinary tract, respiratory system, skin, soft tissues, bones and joints, and gastrointestinal tract affecting patients especially those who are immuno-compromised. The species of Staphylococci used in this evaluation were gram-positive cocci and were facultative anaerobes. Both $S$. aureus and $S$. epidermidis were significant in their interactions with humans. S. aureus may be considered a potential pathogen that may cause superficial skin lesions such as boils, styes and furuncles. The infection can lead to more serious infections such as pneumonia, mastitis, phlebitis, meningitis, and urinary tract infections; and deep-seated infections, such as osteomyelitis and endocarditis. S. aureus is a major cause of hospital acquired nosocomial infection, of food poisoning by releasing enterotoxins into food, and toxic shock syndrome by the release of super antigens into the blood stream. [13].

Meanwhile, S. epidermidis is an inhabitant of the skin. Most of its strains are non-pathogenic and may even play a protective role in humans as normal flora. S. epidermidis may be a pathogen in the hospital environment [13].

\section{Antimicrobial Evaluation Results}

Results of the antimicrobial evaluation of the crude ethanolic root extract on the organisms as shown in Table III indicated that at $1.5 \%$ and $2.0 \%$ concentration, the ethanolic root extract of $S$. spontaneum Linne inhibited the growth of $S$. aureus and S. epidermidis. It can be observed that the zone of inhibition gradually increased as the concentration of the extract increased, indicating an increase in antibacterial activity. However, it was not so with $P$. aeruginosa indicating that the organism was not susceptible to the plant extract. It was also noted that the zone of inhibition was greater for the 
positive control, being a pure material, as compared to the plant extract; hence, the microorganisms have higher susceptibility to the positive control, Diclofenac sodium $1 \%$ gel, than the plant extract.

Antimicrobial evaluation results of the formulated cream as shown in Table IV, containing $0.5 \%, 1.0 \%, 1.5 \%$ and $2.0 \%$ of $S$. spontaneum Linne ethanolic root extract using the same test organisms did not produce any zone of inhibition at any given concentration level; hence, the extract-containing formulated cream does not exhibit antibacterial action on the microorganisms used in the evaluation.

TABLE III: RESULTS OF THE ANTIMICROBIAL EVALUATION OF THE ETHANOLIC ROOT EXTRACT OF S. SPONTANEUM LINN. AND POSITIVE CONTROL, POLYMYXIN B SULFATE + BACITRACIN ZINC + NEOMYCIN

\begin{tabular}{|c|c|}
\hline \multicolumn{2}{|c|}{ Sulfate. } \\
\hline Concentration & Zone of Inhibition (in $\mathrm{mm}$ ) \\
\hline \multicolumn{2}{|c|}{ Staphylococcus aureus } \\
\hline $0.5 \%$ & $0 \pm 0$ \\
\hline $1.0 \%$ & $0 \pm 0$ \\
\hline $1.5 \%$ & $0.14 \pm 0.05$ \\
\hline $2.0 \%$ & $0.29 \pm 0.06$ \\
\hline Positive control & $2.46 \pm 0.12$ \\
\hline Negative control & $0.09 \pm 0.08$ \\
\hline \multicolumn{2}{|c|}{ Staphylococcus epidermidis } \\
\hline $0.5 \%$ & $0 \pm 0$ \\
\hline $1.0 \%$ & $0.13 \pm 0.03$ \\
\hline $1.5 \%$ & $0.32 \pm 0.06$ \\
\hline $2.0 \%$ & $0.52 \pm 0.05$ \\
\hline Positive control & $4.42 \pm 0.10$ \\
\hline Negative control & $0.12 \pm 0.11$ \\
\hline \multicolumn{2}{|c|}{ Pseudomonas aeruginosa } \\
\hline $0.5 \%$ & $0 \pm 0$ \\
\hline $1.0 \%$ & $0 \pm 0$ \\
\hline $1.5 \%$ & $0 \pm 0$ \\
\hline $2.0 \%$ & $0 \pm 0$ \\
\hline Positive control & $1.50 \pm 0.37$ \\
\hline Negative control & $0.04 \pm 0.06$ \\
\hline
\end{tabular}

\section{Results of the Anti-inflammatory Activity Evaluation}

Table $\mathrm{V}$ shows the anti-inflammatory activity evaluation of the formulated $S$. spontaneum Linn. root extract cream at $0.5 \%$ (Group II), $1.0 \%$ (Group III), $1.5 \%$ (Group IV), and $2.0 \%$ (Group V) concentrations, positive control (Group VI) and the negative control (Group I). It was observed that one hour after the application of the samples the inflammation still tends to increase. Two hours after the application, the inflammation decreased for Groups II-VI, except for Group I (control group) indicating no anti-inflammatory activity. It was also observed that the difference in the decrease in paw volume was higher for the positive control group. After the third hour of observation, the difference in the decrease in inflammation was higher for group $\mathrm{V}$ containing $2 \%$ extract of S. spontaneum Linn., than the other treatment groups including the positive control group which showed higher anti-inflammatory activity.

The process of inflammation usually occurs when there is a harmful stimulus like infections, antibodies or physical injuries or a variety of toxic chemical agents. The ensuing condition is usually characterized by warmth, pain, redness and swelling. This process is mediated by different mechanism such as acute phase, characterized by transient local vasodilation and increased capillary permeability; delayed sub-acute phase due to infiltration of leukocytes and phagocytic cells; and chronic phase, wherein tissue degeneration and fibrosis follow [14]. Cell damage associated by inflammation causes leukocytes to release lysosomal enzymes; arachidonic acid and various eicosanoid. The cyclooxygenase pathway of arachidone metabolism produces prostaglandins that affect blood vessels and cells involved in inflammation [15]. The cyclooxygenase isoform especially COX-2 is induced during inflammation, and facilitates inflammatory response [15].

TABLE IV: RESULTS OF ZONE OF INHIBITION OF THE FORMULATED $S$. SPONTANEUM LINN. ROOT EXTRACT CREAM AND POSITIVE CONTROL, POLYMYXIN B SULFATE + BACITRACIN ZINC + NEOMYCIN SULFATE

\begin{tabular}{|c|c|}
\hline Concentration & Zone of Inhibition (in mm) \\
\hline \multicolumn{2}{|c|}{ Staphylococcus aureus } \\
\hline $0.5 \%$ & $0 \pm 0$ \\
\hline $1.0 \%$ & $0 \pm 0$ \\
\hline $1.5 \%$ & $0 \pm 0$ \\
\hline $2.0 \%$ & $0 \pm 0$ \\
\hline Positive control & $2.50 \pm 0.61$ \\
\hline Negative control & $0 \pm 0$ \\
\hline \multicolumn{2}{|c|}{ Staphylococcus epidermidis } \\
\hline $0.5 \%$ & $0 \pm 0$ \\
\hline $1.0 \%$ & $0 \pm 0$ \\
\hline $1.5 \%$ & $0 \pm 0$ \\
\hline $2.0 \%$ & $0 \pm 0$ \\
\hline Positive control & $4.36 \pm 0.76$ \\
\hline Negative control & $0 \pm 0$ \\
\hline \multicolumn{2}{|c|}{ Pseudomonas aeruginosa } \\
\hline $0.5 \%$ & $0 \pm 0$ \\
\hline $1.0 \%$ & $0 \pm 0$ \\
\hline $1.5 \%$ & $0 \pm 0$ \\
\hline $2.0 \%$ & $0 \pm 0$ \\
\hline Positive control & $1.52 \pm 0.52$ \\
\hline Negative control & $0 \pm 0$ \\
\hline
\end{tabular}

TABLE V: DIFFERENCE IN THE VOLUME OF INFLAMMATION AT 1 HOUR, 2

HOURS, AND 3 HOURS AFTER THE APPLICATION OF FORMULATED SACCHARUM SPONTANEUM LINN. ROOT EXTRACT CREAM AND POSITIVE CONTROL

\begin{tabular}{|c|c|c|c|}
\hline \multirow{2}{*}{$\begin{array}{l}\text { Treatment } \\
\text { Group }\end{array}$} & \multicolumn{3}{|c|}{ Volume of inflammation (in mm) } \\
\cline { 2 - 4 } & After 1 Hour & After 2 hours & After 3 hours \\
\hline GROUP 1 & $-0.74 \pm 0.26$ & $-0.23 \pm 0.07$ & $-0.12 \pm 0.11$ \\
\hline GROUP 2 & $-0.87 \pm 0.13$ & $0.33 \pm 0.11$ & $0.12 \pm 0.03$ \\
\hline GROUP 3 & $-0.52 \pm 0.14$ & $0.65 \pm 0.16$ & $0.19 \pm 0.08$ \\
\hline GROUP 4 & $-0.83 \pm 0.12$ & $0.82 \pm 0.16$ & $0.22 \pm 0.08$ \\
\hline GROUP 5 & $-0.75 \pm 0.08$ & $1.08 \pm 0.15$ & $0.47 \pm 0.04$ \\
\hline GROUP 6 & $-0.68 \pm 0.18$ & $1.68 \pm 0.33$ & $0.43 \pm 0.12$ \\
\hline
\end{tabular}


Kinins, neuropeptides, and histamine are released at the site of tissue injury. Oxygen-derived free radicals are produced from stimulated neutrophil membranes. The interaction of these substances to arachidonic acid perpetuates the inflammation [15].

Treatment strategies involve two primary goals, such as, relief and maintenance of symptoms; and slowing the tissue-damaging process [15]. Drugs like NSAID and aspirin affect the inhibition of COX enzymes and prostaglandin biosynthesis. Aspirin modifies COX-1 and COX-2 and irreversibly inhibits cyclooxygenase activity [14]. Drugs like salicylates inhibit the antibody production, antigen-antibody aggregation and antigen-induced release of histamine. Salicylates also influence the metabolism of connective tissues that provides barriers against infection and inflammation [14].

\section{CONCLUSION}

The results obtained showed that the formulated cream containing S. spontaneum Linn. ethanolic root extract has the potential for use as an anti-inflammatory agent rather than being used for its antibacterial property. The $2 \%$ concentration exhibited highest anti-inflammatory effect comparable to the standard cream, Diclofenac sodium $1 \%$ gel (Polymyxin B Sulfate + Bacitracin Zinc + Neomycin Sulfate)

\section{RECOMMENDATIONS}

The researchers recommend the use of other gram positive and gram negative bacteria, ready-made agar plates and comparison standard table to improve results. Skin sensitivity test is recommended to ensure that the pre-formulation would not produce allergic reaction, and to use higher concentrations of the pre-formulation for future evaluation.

\section{REFERENCES}

[1] Bureau of Plant Industry. (2011). Medicinal plant. [Online]. Available: http://www.bpi.da.gov.ph.

[2] W. C. Evans, Trease \& Evan's Pharmacognosy, 16th ed., Singapore: Elsevier Pte Limited, 2010, p. 228, 357.

[3] D. L. Pavia, G. M. Lampman, G. S. Kriz, and R. G. Engel, A Small Scale Approach to Organic Laboratory Techniques, 3rd ed., Australia: Brooks/Cole, Cengage Learning, p. 431.

[4] M. Nihar, S. Ali, and M. Qalsar. (2011). Preliminary phytochemical screening of flowers, leaves, bark, stem and roots of Rhododendron arboretum. Middle-East Journal of Scientific Research. [Online]. 10(4), pp. 472-476. Available: http://idosi.org.mejsr/mejsr10(4)11/9.pdf

[5] L. M. V. Laruan et al., "Phytochemical and antibacterial study of Lagerstroemia speciosa (L.) Pers. and its ethnomedical importance to indigenous communities of Benguet Province," Philippines.Indian Journal of Traditional Knowledge, vol. 12, no. 3, pp. 379-383, 2013.

[6] A. M. Knevel and F. E. DiGangi, Jenkins' Qualitative Pharmaceutical Analysis, 7th ed., New York: McGraw-Hill Book Company, 1977, p. 378.
[7] V. Sabale, H. Kunjwani, and P. Sabale. (2011). Formulation and in vitro evaluation of the topical antiageing preparation of the fruit of Benincasa hispida. J. Ayurveda Integrated Medicine. [Online]. 2(3). pp. 124-128. Available: http://dx.doi.org/10.4103/0975-9476.85550

[8] C. A. Kumar et al., "Psychopharmacological studies on the stem of Saccharum spontaneum," International Journal of Pharm Tech Research., vol. 2, no. 1, pp. 319-321, 2010.

[9] B. Swathy, S. M. Iakshimi, and A. S. Kumar, (2010). Evaluation of analgesic and anti-inflammatory properties of Chloris barbata (SW.). International Journal of Phytopharmacology. [Online]. 1(2), pp. 92-96. Availabe: http://www.onlineijp.com

[10] Todar, K. (2012). Todar's online textbook of bacteriology. [Online]. Available: http://www.textbookof bacteriology.net

[11] L. Brunton, K. Parker, D. Blumenthal, and I. Buxton, Goodman and Gilman's Manual of Pharmacology and Therapeutics, New York: McGraw-Hill Companies, Inc., 2008.

[12] B. G. Katzung, S. B. Masters, and A. J. Trevor, Basic and Clinical Pharmacology, 12th ed. New York: McGraw-Hill Companies, Inc., 2012.

[13] M. Khalid and H. H. Siddiqui. (2011). Pharmacognostical evaluation and qualitative analysis of saccharum spontaneum (L.) root. International Journal of Pharmaceutical Sciences and Drug Research, [Online]. 3(4), 338-341. Available: http://www.ijpsdr.com

[14] J. F. Marriott, K. A. Wilson, C. A. Langley, and D. Belcher, Pharmaceutical Compounding and Dispensing, 2nd ed., London: Pharmaceutical Press, 2010, pp. 153-157.

[15] O. Omar, The Pharmacological and Toxicological Studies of Saccharum spontaneum Linn. (Talahib) Pollens, Manila: Adamson University.

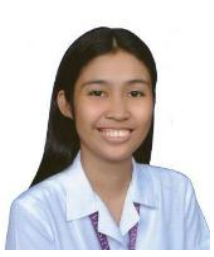

April Mergelle R. Lapuz is a graduate of B.S. in pharmacy from Adamson University, Batch 2015. She was a former auditor and acting secretary of the Adamson University Student Government and the President Emeritus of the Federation of the Junior Chapters of the Philippine Pharmacists' Association Rho Chapter in A.Y. from 2013 to 2014. She plans on pursuing graduate studies in Public Health, and was recently accepted into the program at the Institute of Public Health, UP Manila, and enter the academe after obtaining her Master's degree.

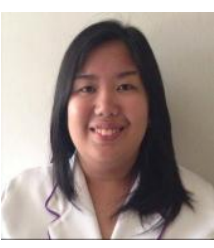

Theriza Marie M. Sembrano is a graduate of B.S. in pharmacy at the College of Pharmacy, Adamson University who wants to become a registered pharmacist someday. She is now preparing for the Pharmacy Licensure Examination. Given the chance, she wanted to excel in research and development.

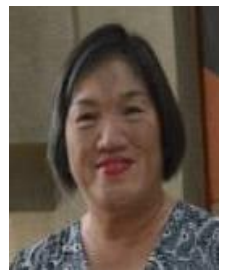

Henedina A. Maini is a graduate of B.S. in pharmacy from the University of the Philippines, Diliman in 1980, and since then has been involved in natural product research dealing with herbal plants exhibiting phototoxic, hypoglycemic and insecticidal activities. She is also a Registered Pharmacist.

She has been involved in natural product research since her graduation and has been teaching Pharmacy undergraduate students since 1989.

Ms. Maini is a regular member of the National Research Council of the Philippines, the Philippine Pharmacists Association and the Philippine Association of Colleges of Pharmacies. 